\title{
Simultaneous pancreas and kidney transplantation as the standard surgical treatment for diabetes mellitus patients with end-stage renal disease
}

\author{
CM Chan, Thomas MY Chim, KC Leung, CH Tong, TF Wong, Gilberto KK Leung *
}

\section{A B S T R A C T}

Objectives: To review the outcome following simultaneous pancreas and kidney transplantation in patients with type 1 diabetes mellitus and endstage renal disease, as well as those with type 2 diabetes mellitus, and to discuss the applicability of this treatment in this locality.

Methods: A systematic literature review was performed by searching the PubMed and Elsevier databases. The search terms used were "simultaneous pancreas and kidney transplantation", "diabetes", "pancreas transplant" and "SPK". Original and major review articles related to simultaneous pancreas and kidney transplantation were reviewed. Papers published in English after 1985 were included. Clinical outcomes following transplantation were extracted for comparison between different treatment methods. Outcomes of simultaneous pancreas and kidney transplant and other transplantation methods were identified and categorised into patient survival, graft survival, diabetic complications, and quality of life. Patient survivals and graft survivals were also compared.

This article was published on 8 Jan 2016 at www.hkmj.org.
Results: Currently available clinical evidence shows good outcomes for type 1 diabetes mellitus in terms of patient survival, graft survival, diabetic complications, and quality of life. For type 2 diabetes mellitus, the efficacy and application of the procedure remain controversial but the outcomes are possibly comparable with those in type 1 diabetes mellitus.

Conclusions: Simultaneous pancreas and kidney transplantation is a technically demanding procedure that is associated with significant complications, and it should be regarded as a 'last resort' treatment in patients whose diabetic complications have become life-threatening or severely burdensome despite best efforts in maintaining good diabetic control through lifestyle modifications and medications.

Hong Kong Med J 2016;22:62-9

DOI: 10.12809/hkmj154613

CM Chan

TMY Chim

KC Leung

CH Tong

TF Wong

GKK Leung *, MB, BS, FHKAM (Surgery)

Centre of Education and Training, Department of Surgery, Li Ka Shing Faculty of Medicine, The University of Hong Kong, Queen Mary Hospital, Hong Kong

* Corresponding author: gilberto@hku.hk

\section{Introduction}

Simultaneous pancreas and kidney transplantation (SPK) has emerged as the worldwide standard for treatment of patients with end-stage renal disease (ESRD) resulting from type 1 diabetes mellitus (T1DM). Multiple studies have shown that SPK can significantly improve both their quality of life (QOL) and long-term survival. With the advances in surgical techniques, immunosuppression, management of graft rejection, and other related complications, SPK can now be performed successfully in the majority of patients, with the pancreatic graft survival rate comparable with those of kidney and liver transplants. ${ }^{1}$ It is currently the predominant type of pancreas transplantation for diabetic patients with ESRD. ${ }^{2}$ According to the International Pancreas Transplant Registry, among over 35000 pancreas transplantations reported by the end of 2010, approximately $75 \%$ were SPK, $18 \%$ were pancreas after kidney transplantation (PAK), and 7\% were pancreas transplantation alone. ${ }^{2}$ The vast majority of SPK performed in various countries used grafts from cadavers, while living donor pancreas and/or kidney grafts were used only in a minority of cases.

In this review, we first discuss the effectiveness of SPK in improving the outcome for diabetic patients with ESRD in comparison with other transplant options including kidney transplant alone (KTA). In addition, we address the controversy about whether patients with type 2 diabetes mellitus (T2DM)associated ESRD, as with T1DM patients, should also receive SPK. This is followed by a discussion on the surgical risks, operative complications, future directions, and the application of this treatment 
approach in this locality. We reviewed original and review articles related to SPK. PubMed and Elsevier databases were searched using the keywords "simultaneous pancreas and kidney transplantation", "diabetes", "pancreas transplant", and "SPK". Articles published in English since 1985 were included.

\section{Outcomes of type 1 diabetes with end-stage renal disease following simultaneous pancreas and kidney transplantation versus kidney transplant alone (living or deceased donor)}

The outcomes of SPK can be assessed in terms of patient survival, graft survival, control of diabetic complications, and improvement in QOL. In the following, comparisons with KTA are made.

\section{Patient survival}

The most important parameter is patient survival. Lindahl et $\mathrm{al}^{3}$ reviewed 15 studies that compared the survival outcomes of SPK, living donor kidney alone (LDKA), and deceased donor kidney alone (DDKA). The authors included nine studies with short-term (up to 10 years) and six studies with long-term (beyond 10 years) follow-up (Table $1^{4-19}$; one more latest short-term study in 2015 was included ${ }^{19}$ ). Overall, most large-scale studies agree that DDKA is inferior to SPK and LDKA. Nonetheless, whether

\section{胰腎聯合移植作為糖尿病患者末期腎病的標準 手術療法}

陳倬銘、詹明鍂、梁家俊、唐智謙、王庭峰、梁嘉傑

目的：分析曾接受胰腎聯合移植的一型糖尿病末期腎病患者的結果, 以及此手術應用於二型糖尿病患者的臨床證據, 並探討這技術在香港 的可行性。

方法：通過PubMed和Elsevier論文搜索引擎進行系統性搜索。用 以搜索文獻的關鍵詞為「胰腎聯合移植」(simultaneous pancreas and kidney transplantation)、「糖尿病」(diabetes)、「胰腺移植」 (pancreas transplant)和 $\ulcorner\mathrm{SPK} 」$ 。原創和較重要的回顧文章均被納入 研究範圍。所有囊括的文章均為1985年後以英文發表的論文。集中搜 集關於移植後的臨床結果來比較不同的治療方法。按胰腎聯合移植和 其他移植方法的臨床結果分為患者生存期、移植物存活期、糖尿病併 發症和生活質量, 並比較患者生存期和移植物存活期

結果：至目前為止臨床試驗的證據顯示胰腎聯合移植於一型糖尿病方 面在患者生存期、移植物存活期、糖尿病併發症和生活質量均有良好 結果。至於二型糖尿病方面, 雖然手術效用和其具體應用仍存在爭 議, 但結果可能與一型糖尿病相若。

結論：胰腎聯合移植技術要求高, 亦可能發生嚴重的併發症, 因此應 經過仔細篩選, 例如當糖尿病併發症已危及病人生命或無法使用藥物 和生理調節控制血糖水平的病人，才施以胰腎聯合移植作為「最後手 段」

SPK or LDKA achieves superior patient survival remains controversial. For short-term outcomes, the overall survival rate of SPK recipients has been shown

TABLE I. Patient survival: summary of studies comparing different transplantation methods $s^{4-19}$

\begin{tabular}{|c|c|c|c|}
\hline & Study, year of publication & No. of patients & Patient survival* \\
\hline \multirow[t]{10}{*}{ Short-term } & Rayhill et al, ${ }^{8} 2000$ & 805 & $\mathrm{SPK}=\mathrm{LDK}>\mathrm{DDK}$ \\
\hline & Ojo et al, ${ }^{9} 2001$ & 9516 & $\mathrm{SPK}=\mathrm{LDK}>\mathrm{DDK}$ \\
\hline & Sutherland et al, ${ }^{10} 2001$ & 396 & $\mathrm{SPK}=\mathrm{LDK}=\mathrm{DDK}$ \\
\hline & Bunnapradist et al, ${ }^{11} 2003$ & 6016 & $\mathrm{SPK}=\mathrm{DDK}$ \\
\hline & Reddy et al, ${ }^{12} 2003$ & 18549 & $\mathrm{SPK}=\mathrm{LDK}>\mathrm{DDK}$ \\
\hline & Waki and Terasaki, ${ }^{13} 2006$ & 1088 & $\mathrm{SPK}=\mathrm{DDK}$ \\
\hline & Young et al, ${ }^{4} 2009$ & 11362 & $\mathrm{LDK}>\mathrm{SPK}=\mathrm{DDK}$ \\
\hline & Weiss et al, ${ }^{14} 2009$ & 8281 & $\mathrm{SPK}+\mathrm{P}>\mathrm{LDK}>\mathrm{SPK}-\mathrm{P}=\mathrm{DDK}$ \\
\hline & Norman et al,,$^{15} 2011$ & 6282 & $\mathrm{SPK}+\mathrm{P}>\mathrm{SPK}-\mathrm{P}$ \\
\hline & Sung et al,,$^{19} 2015$ & 11253 & $\mathrm{SPK}>\mathrm{KTA}$ \\
\hline \multirow[t]{6}{*}{ Long-term } & Becker et al, ${ }^{16} 2000$ & 642 & $\mathrm{SPK}>\mathrm{LDK}>\mathrm{DDK}$ \\
\hline & Mohan et al, ${ }^{17} 2003$ & 101 & $\mathrm{SPK}>\mathrm{DDK}$ \\
\hline & Morath et al, ${ }^{18} 2008$ & 11420 & $\mathrm{SPK}>\mathrm{LDK}>\mathrm{DDK}$ \\
\hline & Sollinger et al,7 2009 & 2100 & $\mathrm{SPK}>\mathrm{LDK}>\mathrm{DDK}$ \\
\hline & Morath et al, ${ }^{5} 2010$ & 15118 & $\mathrm{SPK}>\mathrm{LDK}>\mathrm{DDK}$ \\
\hline & Lindahl et al, ${ }^{6} 2013$ & 630 & SPK > LDK > DDK \\
\hline
\end{tabular}

Abbreviations: DDK = deceased donor kidney; KTA = kidney transplant alone; $\mathrm{LDK}=$ living donor kidney; $\mathrm{SPK}=$ simultaneous pancreas and kidney transplantation; SPK+P = functioning pancreas graft at I year after transplant; SPK-P = no functioning pancreas graft at I year after transplant

* '>' Denotes statistically significantly longer survival, and '=' no statistically significant difference in survival 
to be almost equivalent to that of LDKA recipients, except in one large-scale study by Young et $\mathrm{al}^{4}$ which yielded a better survival rate in LDKA patients after adjustment for high-risk characteristics in this group of patients. Consistent with other studies, the unadjusted overall patient survival was equivalent for SPK and LDKA. For long-term outcomes, SPK recipients had a higher survival rate than LDKA recipients. This may be because the additional beneficial effects of pancreas transplantation on glycaemic control need time to manifest. Morath et $\mathrm{al}^{5}$ postulated that, over time, SPK would provide greater survival benefits since the initially higher associated operational mortalities would later be compensated by improved glycaemic control that reduced death from diabetic complications, particularly in terms of cardiovascular death. This view is further supported by the fact that the major cause of death in all these patients is primarily cardiovascular disease (62\%), followed by infection (16\%), malignancy (8\%), and other causes (14\%). ${ }^{6}$ It also potentially explained why in Young et al's study, ${ }^{4}$ despite initial superior patient survival following LDKA compared with SPK (1-year survival of LDKA, SPK, and DDKA was 97\%, 95\%, and 93\%, respectively), the results began to favour SPK by the end of the 72-month study period.

\section{Graft survival}

The assessment of graft survival in SPK includes that of the kidney and the pancreas. For kidney graft survival, the review by Lindahl et $\mathrm{al}^{3}$ found similar short-term (up to 10 years) kidney graft survival rates following SPK and LDKA; graft survival after DDKA was inferior. Long-term results ( $>10$ years) showed that DDKA was inferior to both SPK and LDKA, and most long-term studies agreed that SPK was equivalent to LDKA, with the exception of a study by Morath et $\mathrm{al}^{5}$ that showed SPK to be superior to LDKA. As such, the current view is that SPK is at least non-inferior to LDKA in terms of long-term kidney graft survival, even though most SPK in the literature reviewed were from cadaver donors (Table $2^{4-6,8,10-20}$.

For pancreas graft survival, the results from SPK have improved significantly over the past years due to improved surgical techniques and immunosuppressive regimens. ${ }^{3}$ Surgical techniques have evolved from the use of pancreatic duct occlusion (1983-1987) to that of exocrine drainage into the urinary bladder (1988-1999), and later to that of direct drainage into the proximal jejunum (2000 onwards). With the latter, the mean pancreas graft survival rates after 1 and 5 years have been reported to be $87 \%$ and $75 \%$, respectively. ${ }^{3}$

\section{Diabetic complications}

In the present context of transplantation therapy, the important complications of T1DM include diabetic nephropathy, diabetic neuropathy, and

TABLE 2. Kidney graft survival: summary of studies comparing different transplantation methods $s^{4-6,8,10-20}$

\begin{tabular}{|c|c|c|c|}
\hline & Study, year of publication & No. of patients & Patient survival* $^{\star}$ \\
\hline \multirow[t]{9}{*}{ Short-term } & Rayhill et al, ${ }^{8} 2000$ & 805 & $\mathrm{SPK}=\mathrm{LDK}>\mathrm{DDK}$ \\
\hline & Sutherland et al, ${ }^{10} 2001$ & 396 & $\mathrm{SPK}=\mathrm{LDK}=\mathrm{DDK}$ \\
\hline & Bunnapradist et al, ${ }^{11} 2003$ & 6016 & $\mathrm{SPK}=\mathrm{DDK}$ \\
\hline & Reddy et al, ${ }^{12} 2003$ & 18549 & $\mathrm{SPK}=\mathrm{LDK}>\mathrm{DDK}$ \\
\hline & Waki and Terasaki, ${ }^{13} 2006$ & 1088 & $\mathrm{SPK}=\mathrm{DDK}$ \\
\hline & Young et al, ${ }^{4} 2009$ & 11362 & $\mathrm{LDK}>\mathrm{SPK}=\mathrm{DDK}$ \\
\hline & Weiss et al, ${ }^{14} 2009$ & 8281 & $\mathrm{SPK}+\mathrm{P}>\mathrm{LDK}>\mathrm{SPK}-\mathrm{P}=\mathrm{DDK}$ \\
\hline & Norman et al, ${ }^{15} 2011$ & 6282 & $\mathrm{SPK}+\mathrm{P}>\mathrm{SPK}-\mathrm{P}$ \\
\hline & Sung et al, ${ }^{19} 2015$ & 11253 & $\mathrm{SPK}>\mathrm{KTA}$ \\
\hline \multirow[t]{6}{*}{ Long-term } & Becker et al, ${ }^{16} 2000$ & 642 & $\mathrm{SPK}=\mathrm{LDK}>\mathrm{DDK}$ \\
\hline & Mohan et al, ${ }^{17} 2003$ & 101 & $\mathrm{SPK}=\mathrm{DDK}$ \\
\hline & Israni et al, ${ }^{20} 2005$ & 8323 & SPK > DDK \\
\hline & Morath et al, ${ }^{18} 2008$ & 11420 & $\mathrm{SPK}=\mathrm{LDK}>\mathrm{DDK}$ \\
\hline & Morath et al, ${ }^{5} 2010$ & 15118 & $\mathrm{SPK}>\mathrm{LDK}>\mathrm{DDK}$ \\
\hline & Lindahl et al, ${ }^{6} 2013$ & 630 & $\mathrm{SPK}=\mathrm{LDK}>\mathrm{DDK}$ \\
\hline
\end{tabular}

Abbreviations: DDK = deceased donor kidney; KTA = kidney transplant alone; LDK = living donor kidney; SPK = simultaneous pancreas and kidney transplantation; SPK $+\mathrm{P}=$ functioning pancreas graft at I year after transplant; SPK-P = no functioning pancreas graft at I year after transplant

* '>' Denotes statistically significantly longer survival, and '=' no statistically significant difference in survival 
an increased risk of cardiovascular diseases. For diabetic nephropathy, several studies have included kidney biopsy in graft assessment following SPK, so as to capture the early diabetes-related changes that might otherwise take time to manifest clinically. The common diabetes-related changes under electron microscopy include thickening of the glomerular basement membrane (GBM) and an increase in mesangial volume. The study by Bohman et $\mathrm{al}^{21}$ was the first to perform kidney biopsy in two SPK patients and six KTA patients. Diabetes-related changes were seen in five of the six KTA recipients but not in any of the SPK recipients. Wilczek et $\mathrm{al}^{22}$ included a larger sample size (20 SPK vs $30 \mathrm{KTA}$ ) with a mean postoperative biopsy time of 1 to 6.8 years. The associated changes under light and electron microscopy were significantly fewer in the SPK group than the KTA group. Bilous et $\mathrm{a}^{23}$ biopsied 12 PAK patients before and at least 1.9 years after the pancreas transplant, and found no glomerular disease progression. They also compared the 12 PAK with 13 KTA patients, and found lower mesangial volume in the PAK group. Although most studies showed that the outcomes would be better in patients with SPK relative to those with KTA, whether the pancreas graft can halt nephropathy progression remains controversial. Nyberg et $\mathrm{al}^{24}$ biopsied 11 SPK patients 2 to 4 years postoperatively, and found a mean increase in GBM thickness when compared with normal controls. While recurrence of diabetic nephropathy is still possible in the long run, current evidence nonetheless supports that SPK can at least delay the progression of diabetic nephropathy in comparison with KTA.

Apart from its effect on the kidney, a pancreas transplant in SPK may potentially improve other organ systems that can be affected by diabetes. Diabetic neuropathy is an example. Navarro et $\mathrm{al}^{25}$ compared 115 pancreas recipients with 92 patients prescribed standard insulin therapy. Neurological status was assessed by clinical examination, nerve conduction studies, and autonomic function test. Results up to 10 years showed significant improvement in nerve conduction studies and slight improvement on clinical examination and autonomic index in the SPK group. We proposed that pancreas transplantation could potentially halt the progression of diabetic neuropathy and may even lead to a degree of neurological improvement.

Besides microvascular complications, macrovascular complications are a major concern in diabetic patients. Cardiovascular diseases, in particular coronary artery disease, contribute to a significant portion of mortality in T1DM patients. Whether SPK can provide benefit in this respect has been studied. Jukema et $\mathrm{al}^{26}$ observed 32 SPK patients with 26 functioning pancreas grafts and six non- functioning pancreas grafts. Glycaemic control was measured by blood glucose level, and the progression of diffuse and focal coronary atherosclerosis was assessed by coronary angiography. It was found that in the presence of a functioning pancreas graft, glycaemic control was better and progression of coronary atherosclerosis was slower. This might also correlate with a lower risk of cardiovascular death and explain why long-term survival in SPK patients is superior to that of KTA patients.

\section{Quality of life}

In addition to survival benefit and reduced comorbidity, improvement in QOL may also represent an important consideration. A functioning pancreas graft can potentially free a patient from the need for self-administered insulin and achieve more stable blood glucose levels. ${ }^{27-29}$ These outcomes may be associated with improvement in QOL. To directly quantify such improvement, some studies have used validated health-related quality of life (HRQOL) questionnaires to evaluate treatment outcomes. The latest cohort study by Martins et $\mathrm{al}^{30}$ compared the HRQOL scores of 126 patients before and after SPK with a follow-up duration of around 5 years. There were improvements in all domains under the Gastrointestinal Quality of Life Index post-transplantation, with a significant visual analogue scale health state improvement from $38 \%$ to $84 \% .{ }^{30}$ Assessment by another tool, the EuroQol-5 Dimension questionnaire, also showed improvement in physical function, psychological status, social function, gastro-intestinal complaints, burden of medical treatment as well as the rate of unemployment. ${ }^{30}$ The majority of available studies have focused mainly on comparison of pre-transplant and post-transplant scores, or on transplanted and non-transplanted patients. Few studies have compared QOL outcomes between patients undergoing SPK and KTA. Sureshkumar et $\mathrm{al}^{31}$ conducted a case-control study involving 27 SPK patients and 27 KTA patients. The authors concluded that SPK patients had a significantly better diabetesrelated QOL.

\section{Considerations in type 1 versus type 2 diabetes mellitus}

\section{Indications (in type 1 versus type 2 diabetes mellitus)}

The predominant indication for SPK is T1DM patients with ESRD and adequate cardiac reserve who have no opportunity for a living donor kidney transplantation. $^{32}$ Currently, most centres will perform SPK mainly for T1DM, less commonly for T2DM patients. Nonetheless there has been pervasive controversy on whether the long-term outcomes of SPK in the two groups actually differ. 
This has important implications in organ allocation as T2DM is much more prevalent than T1DM. Several factors have to be considered. First, there are differences in pathogenesis between the two conditions-T2DM is attributed to insulin resistance in addition to insulin secretion defect; in T1DM, the pathogenesis involves the auto-destruction of islet cells, causing absolute insulin deficiency. This would theoretically render pancreas transplantation less efficacious in T2DM. Second, there is as yet no consensus on the distinction between the two conditions. For example, C-peptide, which is used in patient selection for SPK between T1DM and T2DM patients, has been shown by some studies to be unreliable in determining the outcomes of SPK. ${ }^{33}$ Third, it should be noted that there exists major differences between the two groups of diabetic patients that make meaningful comparison difficult. These include disproportionate sample sizes; the presence of confounders such as age, obesity, comorbidities; and duration and treatment of the underlying diabetes.

Notwithstanding, there has been an increasing amount of evidence showing comparable results of SPK in selected T2DM and T1DM patients. ${ }^{34}$ In a large study using the data obtained from the Organ Procurement and Transplant Network/ United Network for Organ Sharing (OPTN/UNOS) between 2000 and 2007, Sampaio et $\mathrm{al}^{35}$ showed no significant difference in 5-year survival rate between T1DM and T2DM recipients despite the fact that the latter group had a higher risk of death due to older age and longer pre-transplant dialysis time. In the same study, the 5-year pancreas graft survival in T2DM patients $(69.8 \%)$ was comparable with that in T1DM patients (72.4\%); an inferior 5-year kidney graft survival was found $(77.8 \%$ vs $73.5 \% ; \mathrm{P}=0.007) .^{35}$ After adjusting for other potential risk factors (eg time on dialysis, obesity), however, diabetes type was not identified as an independent prognostic

\section{factor. ${ }^{35}$}

Concerning the role of $\mathrm{C}$-peptide in defining T1DM and T2DM during patient selection, Stratta et $\mathrm{al}^{36}$ stratified 162 SPK recipients according to pretransplant C-peptide levels into C-peptide 'positive' $(\geq 2.0 \mathrm{ng} / \mathrm{mL} ; \mathrm{n}=30)$ and $\mathrm{C}$-peptide 'negative' $(<2.0$ $\mathrm{ng} / \mathrm{mL} ; \mathrm{n}=132$ ) groups. With a mean follow-up duration of 5.6 years, the two groups showed no statistically significant differences in pancreas graft, kidney graft, or patient survival. ${ }^{36}$ In a similar study involving 80 SPK recipients, 10 were classified as T2DM and 70 as T1DM. ${ }^{37}$ On Cox regression survival analyses, no statistically significant difference in graft and patient survival was found between the two groups. ${ }^{37}$ The authors concluded that selected T2DM patients with ESRD should be considered potential candidates for SPK, and that the use of Cpeptide as the predominant marker of the diabetes type was unreliable and potentially misleading. ${ }^{37}$

\section{Simultaneous pancreas and kidney transplantation versus other transplant options in type 2 diabetes mellitus patients}

At present, there is insufficient evidence to support the use of SPK over other kidney transplant options in patients with T2DM. In an early study that compared the outcomes of SPK, DDKA, and LDKA in patients with T2DM, Wiseman and Gralla ${ }^{38}$ concluded that both patient and graft survival rates were superior with LDKA transplantation, whereas patient but not graft survival rate was higher in SPK versus DDKA transplantation. After multivariable analysis, the survival advantage of SPK over DDKA was related not so much to the pancreas transplantation but other variables such as younger donor and recipient ages in the SPK cohort (Table $3^{38}$ ). These findings, however, should not completely dismiss the consideration of SPK for selected T2DM patients who have little prospect for LDKA since other outcome measures such as the

TABLE 3. Comparison of outcomes between simultaneous pancreas and kidney transplantation and living/deceased donor kidney alone by Wiseman and Gralla ${ }^{38}$

\begin{tabular}{lccc}
\hline & SPK & Kidney transplantation & P value \\
\hline LDKA & $(\mathrm{n}=424)$ & $(\mathrm{n}=1987)$ & 0.003 \\
\hline Patient survival & $82.0 \%$ & $87.3 \%$ & 0.002 \\
\hline Kidney survival & $75.2 \%$ & $81.2 \%$ & 0.003 \\
Death-censored kidney graft survival & $86.2 \%$ & $91.1 \%$ & $(\mathrm{n}=4005)$ \\
DDKA & $(\mathrm{n}=424)$ & $75.5 \%$ & 0.04 \\
Patient survival & $82.0 \%$ & $65.1 \%$ & 0.004 \\
Kidney survival & $75.2 \%$ & $82.6 \%$ & 0.21 \\
Death-censored kidney graft survival & $86.2 \%$ & & \\
\hline
\end{tabular}

Abbreviations: DDKA = deceased donor kidney alone; LDKA = living donor kidney alone; SPK = simultaneous pancreas and kidney transplantation 
benefits of euglycaemia in terms of better QOL and secondary complications of diabetes will also have to be considered. Nonetheless, given the superior longterm outcome of SPK over LDKA in T1DM patients and that the same has yet to be demonstrated in T2DM patients, T1DM patients should still be given a stronger allocation priority of SPK grafts. ${ }^{3}$

\section{Complications of simultaneous pancreas and kidney transplantation}

Most complications of SPK are related to the transplanted pancreas. $^{39}$ Repeated laparotomy may be required in up to $50 \%$ of patients. ${ }^{40,41}$ The pancreatic graft survival at 1 year may range from $74 \%$ to $88 \%$, with the sharpest drop during the first year. ${ }^{7,39,42}$ The reported 10-year and 20-year survival rates were $63 \%$ and $36 \%$, respectively. ${ }^{7}$ Most complications occur within the first 60 days of operation and include graft pancreatitis (3\%$12 \%)$ infection/abscess (1\%-5\%), focal/diffuse necrosis (12\%), graft-vessel thrombosis (6\%-17\%), anastomotic leak (0.5\%-2\%), and intra-abdominal haemorrhage $(0 \%-0.5 \%){ }^{39-43}$ Venous thrombosis has been reported to be the most common cause of graft failure; graft pancreatitis and focal/diffuse necrosis were the most common causes of mortality among graft-specific complications. ${ }^{39,40}$

Complications related to the transplanted kidney include acute tubular necrosis (ATN) or graft rejection, urinary complications, infection, and vascular thrombosis. According to a study of 112 SPK recipients by Grochowiecki et $\mathrm{al}^{44}$ ATN and rejection were the most frequent (43.4\%) causes leading to the loss of kidney graft function. Infections (28.6\%) and vascular thrombosis due to atherosclerosis of the iliac arteries (28.6\%) were the most common reasons for graft nephrectomy. ${ }^{44}$ The most severe complications were due to fungal infection. ${ }^{44}$ Overall, the 1 -year survival rate for the kidney graft was over $90 \% .^{7,44,45}$ The 10-year and 20 -year kidney survival rates were $63 \%$ and $38 \%$, respectively. ${ }^{7}$ In terms of overall mortality, the most common causes following SPK have been reported to be cardiopulmonary $(7.2 \%)$, followed by infection (3.4\%), stroke (1.8\%), and renal failure (1.5\%). Patient survival rates at 1,10 , and 20 years were $97 \%, 80 \%$, and $58 \%$, respectively. ${ }^{7}$

Comparison of the complications of SPK versus KTA has revealed that SPK has a lower rate of ATN $(8.9 \%)^{44}$ than KTA $(15.3 \%),{ }^{46}$ but a slightly higher rate of urological complications $(4.5 \%)^{44}$ than KTA $(3.7 \%) .{ }^{47}$ The incidence of vascular complications was comparable in SPK $(1.8 \%)^{44}$ and KTA $(0.5 \%$ $4 \%) .{ }^{48-50}$ As mentioned above, SPK has higher longterm patient and kidney survival rates than LDKA/ DDKA.

\section{Future directions and local applicability of simultaneous pancreas and kidney transplantation}

Simultaneous pancreas and kidney transplantation has become an established treatment for patients with T1DM complicated by ESRD. The results have, so far, been promising. Furthermore, apart from SPK, newer techniques including pancreatic islet cell transplantation, and different combinations of living and/or deceased donor pancreas, islet cell and kidney graft transplantation are being evaluated. Current research aims to extend these techniques, still predominantly SPK, to the treatment of T2DM, for which LDKA remains the first-line treatment option. In situations where LDKA is not available for T2DM patients, DDKA remains the next best option. Regarding the ethical issues about graft allocation, the allocation of DDKA is based on an allocation system that takes account of patient age and waiting time as well as the degree of human leukocyte antigen (HLA) matching between the potential donor and the recipient. ${ }^{51}$ Difficulties may arise, however, when a deceased donor with both kidney and a pancreas graft has become available. Should the priority for these grafts be given to a patient on the SPK waiting list or a non-diabetes-related ESRD patient on the DDKA waiting list? And should the priority of SPK be given to a T2DM patient who is higher up on the allocation system (with a younger age, a longer waiting time, or lesser degree of HLA mismatch) or to a T1DM patient who is lower on the allocation system but is more likely to achieve a better outcome? The related ethical issues clearly deserve an informed discourse within the surgical community.

Simultaneous pancreas and kidney transplantation has not yet been performed in this locality. The main obstacle remains the shortage of cadaver organs. Here, the number of cadaveric renal transplantations performed in the Hospital Authority over the last decade ranges from 44 to 87 cases per year. As of 31 December 2014, the number of patients waiting for transplantation was close to 2000. This translates into significantly prolonged dialysis time for this specific group of patients, and hence a potentially suboptimal outcome after SPK. The implementation of SPK would not be readily feasible unless there is a significant improvement in organ availability.

\section{Conclusions}

Simultaneous pancreas and kidney transplantation has become a standard treatment worldwide for patients with T1DM and ESRD. There is a large volume of clinical evidence supporting good 
outcomes in patient survival, graft survival, diabetic complications, and QOL. For T2DM, the efficacy and application of the procedure remain controversial but the outcomes are possibly comparable to that in T1DM. Simultaneous pancreas and kidney transplantation is a technically demanding procedure that is associated with significant complications, and should be undertaken only in carefully selected patients. It should be regarded as a 'last resort' treatment for patients in whom diabetic complications have become life-threatening or severely burdensome despite best efforts in maintaining good diabetic control through lifestyle modification and medications. Continued efforts in patient education and the promotion of an altruistic culture of organ donation among the public are critical for the implementation of this treatment paradigm in this locality.

\section{References}

1. Redfield RR, Scalea JR, Odorico JS. Simultaneous pancreas and kidney transplantation: current trends and future directions. Curr Opin Organ Transplant 2015;20:94-102.

2. Gruessner AC. 2011 Update on pancreas transplantation comprehensive trend analysis of 25,000 cases followed up over the course of twenty-four years at the International Pancreas Transplant Registry (IPTR). Rev Diabet Stud 2011;8:6-16.

3. Lindahl JP, Jenssen T, Hartmann A. Long-term outcomes after organ transplantation in diabetic end-stage renal disease. Diabetes Res Clin Pract 2014;105:14-21.

4. Young BY, Gill J, Huang E, et al. Living donor kidney versus simultaneous pancreas-kidney transplant in type I diabetics: an analysis of the OPTN/UNOS database. Clin J Am Soc Nephrol 2009;4:845-52.

5. Morath C, Zeier M, Döhler B, et al. Transplantation of the type 1 diabetic patient: the long-term benefit of a functioning pancreas allograft. Clin J Am Soc Nephrol 2010;5:549-52.

6. Lindahl JP, Hartmann A, Horneland R, et al. Improved patient survival with simultaneous pancreas and kidney transplantation in recipients with diabetic end-stage renal disease. Diabetologia 2013;56:1364-71.

7. Sollinger HW, Odorico JS, Becker YT, D’Alessandro AM, Pirsch JD. One thousand simultaneous pancreas-kidney transplants at a single center with 22-year follow-up. Ann Surg 2009;250:618-30.

8. Rayhill SC, D'Alessandro AM, Odorico JS, et al Simultaneous pancreas-kidney transplantation and living related donor renal transplantation in patients with diabetes: is there a difference in survival? Ann Surg 2000;231:417-23.

9. Ojo AO, Meier-Kriesche HU, Hanson JA, et al. The impact of simultaneous pancreas-kidney transplantation on longterm patient survival. Transplantation 2001;71:82-90.

10. Sutherland DE, Gruessner RW, Dunn DL, et al. Lessons learned from more than 1,000 pancreas transplants at a single institution. Ann Surg 2001;233:463-501.

11. Bunnapradist S, Cho YW, Cecka JM, Wilkinson A, Danovitch GM. Kidney allograft and patient survival in type I diabetic recipients of cadaveric kidney alone versus simultaneous pancreas kidney transplants: a multivariate analysis of the UNOS database. J Am Soc Nephrol 2003;14:208-13.

12. Reddy KS, Stablein D, Taranto S, et al. Long-term survival following simultaneous kidney-pancreas transplantation versus kidney transplantation alone in patients with type 1 diabetes mellitus and renal failure. Am J Kidney Dis 2003;41:464-70

13. Waki K, Terasaki PI. Kidney graft and patient survival with and without a simultaneous pancreas utilizing contralateral kidneys from the same donor. Diabetes Care 2006;29:16702.

14. Weiss AS, Smits G, Wiseman AC. Twelve-month pancreas graft function significantly influences survival following simultaneous pancreas-kidney transplantation. Clin J Am Soc Nephrol 2009;4:988-95.

15. Norman SP, Kommareddi M, Ojo AO, Luan FL. Early pancreas graft failure is associated with inferior late clinical outcomes after simultaneous kidney-pancreas transplantation. Transplantation 2011;92:796-801.

16. Becker BN, Brazy PC, Becker YT, et al. Simultaneous pancreas-kidney transplantation reduces excess mortality in type 1 diabetic patients with end-stage renal disease. Kidney Int 2000;57:2129-35.

17. Mohan P, Safi K, Little DM, et al. Improved patient survival in recipients of simultaneous pancreas-kidney transplant compared with kidney transplant alone in patients with type 1 diabetes mellitus and end-stage renal disease. $\mathrm{Br} \mathrm{J}$ Surg 2003;90:1137-41.

18. Morath C, Zeier M, Döhler B, Schmidt J, Nawroth PP, Opelz G. Metabolic control improves long-term renal allograft and patient survival in type 1 diabetes. J Am Soc Nephrol 2008;19:1557-63.

19. Sung RS, Zhang M, Schaubel DE, Shu X, Magee JC. A reassessment of the survival advantage of simultaneous kidney-pancreas versus kidney-alone transplantation. Transplantation 2015;99:1900-6.

20. Israni AK, Feldman HI, Propert KJ, Leonard M, Mange KC. Impact of simultaneous kidney-pancreas transplant and timing of transplant on kidney allograft survival. Am J Transplant 2005;5:374-82.

21. Bohman SO, Tydén G, Wilczek $\mathrm{H}$, et al. Prevention of kidney graft diabetic nephropathy by pancreas transplantation in man. Diabetes 1985;34:306-8.

22. Wilczek HE, Jaremko G, Tydén G, Groth CG. Evolution of diabetic nephropathy in kidney grafts. Evidence that a simultaneously transplanted pancreas exerts a protective effect. Transplantation 1995;59:51-7.

23. Bilous RW, Mauer SM, Sutherland DE, Najarian JS, Goetz FC, Steffes MW. The effects of pancreas transplantation on the glomerular structure of renal allografts in patients with insulin-dependent diabetes. N Engl J Med 1989;321:805.

24. Nyberg G, Holdaas H, Brekke IB, et al. Glomerular ultrastructure in kidneys transplanted simultaneously with a segmental pancreas to patients with type 1 diabetes. Nephrol Dial Transplant 1996;11:1029-33.

25. Navarro X, Sutherland DE, Kennedy WR. Long-term effects of pancreatic transplantation on diabetic neuropathy. Ann Neurol 1997;42:727-36

26. Jukema JW, Smets YF, van der Pijl JW, et al. Impact of simultaneous pancreas and kidney transplantation on progression of coronary atherosclerosis in patients with 
end-stage renal failure due to type 1 diabetes. Diabetes Care 2002;25:906-11.

27. Robertson RP, Sutherland DE, Kendall DM, Teuscher AU, Gruessner RW, Gruessner A. Metabolic characterization of long-term successful pancreas transplants in type I diabetes. J Investig Med 1996;44:549-55.

28. Robertson RP, Holohan TV, Genuth S. Therapeutic controversy: Pancreas transplantation for type I diabetes. J Clin Endocrinol Metab 1998;83:1868-74.

29. Drognitz O, Benz S, Pfeffer F, et al. Long-term followup of 78 simultaneous pancreas-kidney transplants at a single-center institution in Europe. Transplantation 2004;78:1802-8

30. Martins LS, Outerelo C, Malheiro J, et al. Health-related quality of life may improve after transplantation in pancreas-kidney recipients. Clin Transplant 2015;29:24251.

31. Sureshkumar KK, Mubin T, Mikhael N, Kashif MA, Nghiem DD, Marcus RJ. Assessment of quality of life after simultaneous pancreas-kidney transplantation. Am J Kidney Dis 2002;39:1300-6.

32. Larsen JL. Pancreas transplantation: indications and consequences. Endo Rev 2004;25:919-46.

33. Knight RJ, Lawless A, Patel SJ, Gaber AO. Simultaneous kidney-pancreas transplantation for end-stage renal disease patients with insulin-dependent diabetes and detectable C-peptide. Transplant Proc 2010;42:4195-6.

34. Weems P, Cooper M. Pancreas transplantation in type II diabetes mellitus. World J Transplant 2014;4:216-21.

35. Sampaio MS, Kuo HT, Bunnapradist S. Outcomes of simultaneous pancreas-kidney transplantation in type 2 diabetic recipients. Clin J Am Soc Nephrol 2011;6:1198206.

36. Stratta RJ, Rogers J, Farney AC, et al. Pancreas transplantation in C-peptide positive patients: does "type" of diabetes really matter? J Am Coll Surg 2015;220:716-27.

37. Chakkera HA, Bodner JK, Heilman RL, et al. Outcomes after simultaneous pancreas and kidney transplantation and the discriminative ability of the $\mathrm{C}$-peptide measurement pretransplant among type 1 and type 2 diabetes mellitus. Transplant Proc 2010;42:2650-2.

38. Wiseman AC, Gralla J. Simultaneous pancreas kidney transplant versus other kidney transplant options in patients with type 2 diabetes. Clin J Am Soc Nephrol 2012;7:656-64.

39. Grochowiecki T, Gałązka Z, Madej K, et al. Surgical complications related to transplanted pancreas after simultaneous pancreas and kidney transplantation. Transplant Proc 2014;46:2818-21.

40. Sansalone CV, Maione G, Aseni P, et al. Surgical complications are the main cause of pancreatic allograft loss in pancreas-kidney transplant recipients. Transplant Proc 2005;37:2651-3.

41. Michalak G, Kwiatkowski A, Czerwinski J, et al. Surgical complications of simultaneous pancreas-kidney transplantation: a 16-year-experience at one center. Transplant Proc 2005;37:3555-7.

42. Gruessner AC, Sutherland DE, Gruessner RW. Pancreas transplantation in the United States: a review. Curr Opin Organ Transplant 2010;15:93-101.

43. Malaise J, Steurer W, Koenigsrainer A, et al. Simultaneous pancreas-kidney transplantation in a large multicenter study: surgical complications. Transplant Proc 2005;37:2859-60.

44. Grochowiecki T, Gałązka Z, Madej K, et al. Early complications related to the transplanted kidney after simultaneous pancreas and kidney transplantation. Transplant Proc 2014;46:2815-7.

45. Campos Hernández JP, Gómez Gómez E, Carrasco Valiente $\mathrm{J}$, et al. Influence of surgical complications on kidney graft survival in recipients of simultaneous pancreas kidney transplantation. Transplant Proc 2015;47:112-6.

46. Ounissi M, Gargah T, Barbouch S, et al. Acute tubular necrosis in kidney transplantation [in French]. Tunis Med 2012;90:463-7.

47. Samhan M, Al-Mousawi M, Hayati H, Abdulhalim M, Nampoory MR. Urologic complications after renal transplantation. Transplant Proc 2005;37:3075-6.

48. Renoult E, Amicabile C, Jonon B, Kessler M, L'Hermite J. Early and recurrent venous graft thrombosis after kidney transplantation: benefit of an early surgery. Clin Nephrol 1990;34:236-7.

49. Bretan PN, Burke EC. Renal transplantation. In: Tanagho EA, Mc Annich JW, editors. Smith's general urology. London: Appleton and Lange; 1995: 612-24.

50. Kribs SW, Rankin RN. Doppler ultrasonography after renal transplantation: value of reversed diastolic flow in diagnosing renal vein obstruction. Can Assoc Radiol J 1993;44:434-8.

51. Hawkins BR. A point score system for allocating cadaveric kidneys for transplantation based on patient age, waiting time and HLA match. Hong Kong J Nephrol 2004;2:79-83. 